\title{
ESTUDIO DE LA MUJER EN LA OBRA DE GIOVANNI VERGA
}

\author{
STUDY OF THE WOMAN IN GIOVANNI VERGA'S WORK
}

María Reyes Ferrer

Universidad de Murcia

\section{Resumen:}

El presente estudio tiene como objetivo analizar los personajes femeninos en la obra del escritor siciliano Giovanni Verga. Para ello, se han tenido en cuenta las representaciones literarias de la mujer angelical y la mujer fatal, dos prototipos femeninos que aparecen reflejados en sus obras y que evidencian los dos extremos de la experiencia femenina en la cultura patriarcal.

\section{Palabras Claves:}

Giovanni Verga, mujer fatal, ángel del hogar, muerte.

\section{Abstract:}

The present study aims to analyze the female characters in the work of the Sicilian writer Giovanni Verga. In order to do so, we have taken into account the literary representations of the angelic woman and the femme fatale, two feminine prototypes that are reflected in his works and show both extremes of the feminine experience in the patriarchal culture.

\section{KEY WORD:}

Giovanni Verga, femme fatale, angelic woman, death. 


\section{INTRODUCCIÓN}

Giovanni Verga nació en el año 1840 en Catania, Sicilia, y alcanzó una notable fama como escritor dentro de la corriente literaria del verismo, una tendencia que nació en Italia después de la unificación del país que tuvo lugar en 1860. De esta nueva corriente, que se inspira en el naturalismo francés, se puede destacar su rigurosa fidelidad a la realidad, a lo verdadero, de los hechos, de los personajes, de los medios...en la sociedad. Verga, al igual que otros veristas, tendió a plasmar en sus obras la realidad, sobre todo, un ambiente rural, campesino, humilde, marginal en ocasiones, y encontró en Sicilia un ambiente perfecto para llevar a cabo su labor. La región meridional quedó visiblemente marginada tras la unificación de Italia y conservaba unas costumbres arraigadas propias de la vida campesina, conformando un mosaico de historias y tradiciones de gran interés literario. Además, otra de las principales características del verismo es su marcado carácter regionalista. El autor busca un fiel retrato de la realidad, intenta hacer que sus personajes hablen por si mismos sin dejar ningún tipo de huella del autor, es decir, configura una historia en torno a un relato impersonal. De hecho, si fuera necesario, Verga usará el lenguaje vulgar, dialectos, para hacerlo más real. Por ello, el estilo de Verga recuerda a las marionetas: una similitud con personajes reales, pero siempre hay alguien que mueve los hilos.

Al empezar a leer el trabajo de Giovanni Verga, llaman la atención de manera particular las protagonistas femeninas, ya que todas ellas suelen ser mujeres turbadas, problemáticas y/o con problemas, víctimas, cada una a su modo, de una sociedad claramente patriarcal, y protagonistas de un final con tintes dramáticos. Se observa que las obras de Verga ofrecen una visión de la mujer muy diversa, pero que coincide con una visión de la mujer muy extendida en la literatura europea del siglo XIX: la dicotomía entre Madonna y Magdalena, es decir, la representación de la mujer en su positivismo o negativismo absoluto simbolizada en una pirámide de modelos femeninos ${ }^{1}$.

En la cúspide de la pirámide nos encontramos esas mujeres que nos recuerdan a los ángeles, a la virgen (Madonnas), un prototipo de mujer pura, humilde, virtuosa, asexual, que se ocupa de su hogar y dentro de él, de la moralidad, de la educación de los hijos y de cuidar y obedecer al marido. Es decir, se describe una mujer que actúa dentro de un campo de acción limitado, como ya se ha dicho, de la esfera privada, donde ejercen su influencia como madres, esposas e hijas capaces de amar y sufrir en silencio; mujeres sacrificadas y resignadas, que renuncian a su vida para cuidar de sus hijos y satisfacer los deseos de sus maridos.

1 Cfr. Persico, G. (2011). Madonne, Maddalene ealtre vittoriane. Modelli femminili nella letteratura inglese al tempo della regina Vittoria. I testi i il contesto, Agora \& Co: Roma.
En la base de la pirámide nos encontramos con el lado opuesto: Las Magdalenas, mujeres pecadoras, desposeídas de virtudes, con gran capacidad de seducción, que se identifican con la sexualidad y lo carnal y no con los valores establecidos por la sociedad. Una de las figuras más recurrentes es la mujer fatal, que usa su cuerpo como instrumento para seducir y conseguir sus deseos. Suelen estar marginadas de la sociedad y fuera del ámbito familiar, desplazadas socialmente por el miedo a corromper a otros miembros de la sociedad. Se les caracteriza por la falta de identidad, la imposibilidad de autorregularse y de mantener el control de sí mismas. Muchas veces están representadas como fieras, con el uso de animales feroces, como lobos, víboras, serpientes... e incluso el demonio. Sus posibilidades de reinsertarse en la sociedad son mínimas y generalmente la muerte se ve como la única solución para salvar sus almas. La mitad de la pirámide la ocupan las "otras" mujeres, mujeres en medio de dos realidades, que viven en una eterna contradicción y que no se identifican en ninguno de los roles femeninos.

En la obra de Verga, encontramos diversos personajes femeninos, casi todos ellos inspirados en personajes reales y que el autor adaptó al personaje literario y dan como resultado este mosaico de modelos femeninos. Estos personajes femeninos son, a su vez, fruto de la visión subjetiva que Verga tiene de la mujer. La finalidad del estudio es, por tanto, analizar la representación de los personajes femeninos que aparecen en cuatro obras de Giovanni Verga que son: Historia de una curruca, Nedda, El marido de Elena y La Loba. A pesar de que las obras pertenecen a períodos distintos en la carrera de Verga, la mujer ocupa siempre un espacio visible en sus obras.

En primer lugar, trataré Historia de una curruca y Nedda, dos ejemplos de mujeres virtuosas, sacrificadas y resignadas cada una a su manera, y el segundo lugar trataré El marido de Elena y la Loba, dos casos en los que se representa a la mujer fatal

\section{VIRTUOSAS Y SACRIFICADAS: MARÍA Y NEDDA}

\section{Historia de una curruca: El caso de María}

Historia de una curruca es una novela epistolar en la que María, la protagonista, una novicia de 19 años de un convento de Catania (Sicilia) escribe cartas a su amiga Marianna contándole sus experiencias fuera del convento, en Monte Ilice, donde se refugia con su familia, con su padre, su madrastra y sus hermanastros, para escapar de la epidemia del cólera que amenaza la zona. Poco a poco, en las cartas, se deja entrever la personalidad de María, sus vivencias y la manera en la que le cambia la vida al salir del convento. El único problema es que la protagonista, una vez que conoce las dos realidades y experimenta nuevas sensaciones, como el calor de una familia y el amor, se queda entre los dos mundos: el del convento y la vida pública, dos realidades 
irreconciliables. Pasa de la más absoluta resignación y represión de sí misma -una vida marcada por la soledad, subordinación y represión- a la libertad, a vivir sin sacrificios y experimentar el placer sensorial, nunca físico, la estimulación de los sentidos y la belleza de la vida, sin saber distinguir el bien del mal.

María se presenta como una chica inocente, humilde, de gran bondad e ignorante de la realidad que rodea al convento, ya que lleva toda su vida encerrada en él. En una de sus cartas a Marianna, María hace una reflexión sobre su debilidad y se describe como "un pobre corazón débil y tímido, a quien todos los placeres del mundo le pueden hacer un mal inmenso. Una humilde florecita acostumbrada a la que el aire libre la podría matar" (2015: 25)². El personaje de María nos recuerda al de un ángel, una mujer buena, pura, que se preocupa por su alma y se despreocupa de su cuerpo. María siempre aparece vestida con una túnica negra que no deja ver nada de su figura de mujer, se desposee de su cuerpo para dedicarse a la pureza de su alma, siempre dispuesta a hacer el bien. Ya desde el principio de la novela, María se debate entre el mundo del bien y del mal, y empieza a cuestionarse si todo aquello que experimenta y le provoca una satisfacción y placer es bueno o no. En las cartas refleja pensamientos como: “ ¿y si estos placeres fueran un pecado? ¿Y si el señor me viera preferir el campo, el aire libre, la familia al convento, al silencio, a la soledad, al recogimiento?" "Me atormentan estas incertezas" "Marianna, si supieras el pecado que he cometido...he bailado" (45).

El origen de todas las dudas que asaltan a María está ligado a la vida del convento que es una vida de resignación, que conlleva la pérdida de la identidad y la carencia de cualquier tipo de placer, ya que, como ya he comentado al principio de la charla, una mujer que sufre y renuncia a si misma, es una mujer virtuosa.

Un acontecimiento que cambia la vida de María por completo y acentúa su sentimiento de culpabilidad es cuando conoce a Nino y se enamora de él. María aún se muestra más turbada cuando sabe que ese amor es correspondido y que la única manera de poder ser feliz será abandonando el convento y viviendo su vida. Por desgracia, María sabe que es presa de un destino inevitable, un destino que fue elegido por su padre y desobedecerlo conllevaría la deshonra de la familia y la exclusión social y familiar de María; se convertiría en una pecadora y, una mujer débil como ella no lo soportaría. La consecuencia de todo esto es que María no quiere entrar al convento pero tampoco se puede rebelar ante su destino y acepta su entrada de nuevo. Una María que, recordando la pirámide, se sitúa en el centro, entre las mujeres que no se definen con un prototipo.

Ante toda esta situación, crece en María la insubordinación, no del cuerpo, sino del alma. Para poder frenar ese descontrol de sentimientos y el dolor de la renuncia

\footnotetext{
2 La versión que se ha utilizado para el presente estudio es la edición del 2015 (ver bibliografía)
}

a Nino y a la vida deseada, María castiga y agota el cuerpo con el ayuno, para poder agotar así el alma también. La protagonista expía su culpa martirizando su cuerpo para mantener una mente pura.

Al final de la obra, vemos a una María totalmente desequilibrada, salvaje, cercana a esa imagen de mujer fatal, que ya no se identifica con una florecilla, como al inicio, sino con una fiera, un tigre incluso con el demonio. Una María que ya no se guía por la moral y por la razón, sino por la pasión que siente por Nino y la frustración, incluso odio, que siente cuando su hermanastra se casa con éste.

Tras este episodio, el destino de María es trágico ya que, como única salvación posible para el alma de María, muere. La muerte se ve la única manera de rescatar el alma angelical y pura corrompida por las influencias del mundo exterior. La historia de María no pretende moralizar ni dar una lección directamente de la mano de Giovanni Verga; pero lo que sí queda explícito es que la sucesión de hechos de la vida de María tiene que resolverse de un modo ejemplar y que toda experiencia fuera de las convenciones sociales tiene su sanción. Es decir, la sanción de la culpa de María provoca en el lector el reconocimiento de la justicia. Pero ¿Qué tipo de justicia es la que se le hace a María? Veamos otro caso parecido, el caso de Nedda.

El CASO de NedDA.

La historia de Nedda, protagonista de la novela epónima, es la historia de una chica simple, inocente que se dedica a la recogida de la oliva para llevar dinero a casa y ayudar a la madre enferma que, poco tiempo después, morirá. A raíz de la muerte de la madre, Nedda igualmente continúa buscando un trabajo para subsistir pero, esta vez, con el apoyo de Janu, un campesino del que se enamora y le ayuda. Por desgracia, Janu cae enfermo de malaria y muere. Desde una perspectiva social, Nedda se queda totalmente sola, es decir, sin una madre a quien cuidar o en quien apoyarse, -sin una protección en el hogar- y sin una figura masculina que la proteja o le ayude. Además, la situación de Nedda se complica ya que se queda embarazada de Janu, sin haberse casado y sin haber formalizado la situación. Este hecho confirmará la exclusión social de Nedda y la imposibilidad para reinsertarse en ella. Nedda no consigue trabajo, no sólo por su marginación social, sino porque una mujer embarazada, en el campo, no es mano de obra productiva. Cuando el bebé nace, Nedda llora al ver que es una niña y ve su trágica historia reflejada en su hija, que nace raquítica y con problemas. La historia de Nedda acaba con la muerte de la hija, dejando a Nedda totalmente sola y en la miseria.

La descripción física de Nedda coincide con su miserable condición social: una chica morena, vestida pobremente con una actitud tímida que le lleva al aislamiento. Habla también de sus ojos, que podrían ser bonitos si la miseria y la continua resignación 
no los hubieran modificado. Respecto al físico, habla de un cuerpo en el que se dejan ver las fatigas y dificultades de la vida además de las consecuencias de realizar duros trabajos. La consecuencia de esto es la deformación y el endurecimiento del cuerpo, alma e inteligencia y había sido así en su madre, su abuela y así sería en su hija. Las generaciones de mujeres en su familia sufren de un destino irrevocable: las hijas tienen el mismo fin que las madres. La narración enfatiza la brutalidad del cuerpo, un cuerpo que se describe casi desforme por el trabajo, un cuerpo que no nos deja saber la edad de Nedda pero se asume que está lleno de fatigas; encontramos con un alma pura, humilde y trabajadora en un cuerpo casi deforme. Otra vez, como en el caso de María, la apariencia física queda relegada a un segundo plano y lo que importa es el poder de sacrificio del personaje.

El personaje de Nedda representa la humildad, la timidez y la resignación de las mujeres más humildes. La paciencia, el silencio, la falta de protesta y de crítica son los valores que mejor definen a Nedda, junto con el sacrificio que hace por la madre. La humildad de Nedda, en este caso, aparece muy ligada a la humillación. Su humildad comporta una subordinación voluntaria.

Algunos ejemplos en los que se demuestra la humildad de Nedda y su poder de sacrificio, como una mujer angélica son: en primer lugar, Nedda siempre se queda la última para recibir comida, aunque sabe que recibirá menos, ella está acostumbrada y no hace nada para cambiarlo. Representa la abnegación, la escasa importancia que le da a ella misma, al alimento del cuerpo; Nedda sólo quiere dinero para mantener a su madre, el resto no es primordial. Se refleja su sacrificio y dedicación por su madre. En segundo lugar, las chicas del pueblo hablaron mal de ella porque el día después de la muerte de la madre fue a trabajar. Nedda prefiere ir a trabajar honradamente para devolver el dinero que le habían prestado; en este caso su humildad se ve humillada; su capacidad de sacrificio se critica en la sociedad, que no entiende que alguien tan humilde como Nedda y sin recursos no puede estar en casa un día sin trabajar. Y, por último, cuando Nedda, embarazada, busca trabajo y es humillada por ello. Otra vez, esa capacidad de sacrificio, ese instinto maternal de buscar trabajo estando embarazada para poder mantener a su hija se ve humillado por la sociedad.

Estos, y algunos otros casos más de humildad humillada aparecen en Nedda como experiencias de la protagonista. Además, un rasgo curioso en el personaje de Nedda es que, a pesar de su humildad y poder de sacrificio, no se le premia con el reino de los cielos, con un alivio al final de su vida o la reconciliación con la sociedad. Nedda sufrirá sus miserias hasta el final de su vida; es una mujer enajenada de la sociedad, tanto en la esfera privada como en la pública. Por lo tanto, no encuentra un lugar y no porque con su capacidad de sacrificio no lo busque sino porque la sociedad le ha dado la espalda. A todo ello cabría añadirle que Nedda no se rebela no porque no pueda, sino porque no quiere, porque una vez muerta la madre, Janu y su hija, Nedda ha elaborado una idea de la vida como una injusticia, como miserable. Por lo tanto, se podría apuntar a Nedda como una víctima de su propia resignación y de su voluntad. Pero, a mi parecer y teniendo en cuenta la situación de Nedda, la rebelión le hubiera servido para ser condenada abiertamente por su persona, su naturaleza de mujer y no por sus actos.

En este caso, al contrario que en el caso de María, Nedda no muere, pero sí lo hacen Janu y su hija. La muerte aparece otra vez, no como la salvación de su alma, sino como lección de vida: las cosas mal hechas no pueden acabar bien. La muerte de Janu confirma su exclusión social; ahora está sola y embarazada. Por otra parte, la muerte de la hija le da un respiro, aunque no por ello sea más feliz, pero si le alivia pensar que su hija no tendrá que pasar por el tormento y el sufrimiento que ha pasado su madre, su abuela... Incluso al final, llega a exclamar "Oh, benditas vosotras que estáis muertas! Oh, bendita sea la Virgen Santa! Que me habéis quitado mi criatura para no hacerla sufrir como a mí" (1984: 549). Una madre que no puede mantenerse a si misma es imposible que mantenga a su descendencia. Por último, existe un factor común en la vida de Nedda y de María. La característica que tienen en común es que ambas son huérfanas, y ambas están condicionadas por ello y esta ausencia repercutirá directamente en sus vidas.

En el caso de María, el padre le manda al convento a la edad de 7 años ya que la madre había muerto y, como María le cuenta a Marianna, su padre es un humilde trabajador y no se puede hacer cargo de ella. Pero, cuando María sale del convento, sabe que el padre ha formado otra familia, tiene esposa y dos hijos. Entonces, ¿por qué el padre no se hace cargo de María, si puede mantener a la otra familia? Podría ser porque la pérdida de la madre indica la pérdida de la educadora, de la encargada del hogar, como ya se indicó al principio. El padre, decide que alguien se encargue de su educación y formación. Por lo tanto, María está condenada a un destino no elegido por ella.

En el caso de Nedda, esta no es huérfana de madre, pero sí tiene una madre "incapacitada" para ejercer como tal debido a su enfermedad. Además, en el relato no sabemos nada del padre, pero de lo que sí tenemos constancia desde el principio es de la enfermedad de la madre y la desgracia de Nedda, que parte de sus miserias se deben al sacrificio que hace por la madre. Cuando Nedda se queda huérfana de madre, su vida estará rodeada de desgracias. Por lo tanto, al contrario que María, al no tener una figura masculina que lleve el dinero a casa y que se desenvuelva socialmente, Nedda es la encargada de actuar tanto en la esfera pública como privada, ya que la incapacidad de la madre enferma repercute en su vida. 
La trágica figura de las huérfanas, especialmente de madre, es muy recurrente en la obra de escritores dentro y fuera de Italia, como en la tradición sentimental que esta reflejada en la obra del gran novelista inglés, Charles Dickens.

\section{Mujeres fatales: ElenA Y LA LOBA}

\section{IL MARITO DI ELENA}

La figura de Elena es totalmente diversa a las dos protagonistas femeninas que hemos visto anteriormente. Elena nace en una familia burguesa donde recibe una buena educación y a ello se le une su extraordinaria belleza. Elena conoce a un joven, un estudiante de derecho llamado Cesare Donello, del que se enamora. Cuando éste se licencia, pide la mano de Elena, pero sus padres no consienten el matrimonio debido a que Cesare todavía no había alcanzado una posición acomodada para poder dar a Elena una vida plena y satisfactoria. Por ello, deciden huir. A partir de ahí comienzan sus dificultades, unidas al carácter frívolo y ambicioso de Elena que empezará a atormentar sus vidas; ella estaba acostumbrada a una vida de burguesa y no a la vida provincial y modesta. Esto desata en ella su irritación e intriga por el mundo del lujo. Cuando Cesare consigue consolidarse como abogado, Elena aprovecha para realizar su sueño de una vida llena de lujos y superficialidad. Además, todo ello ligado a su gran belleza y la admiración que ésta despierta en los hombres de su alrededor. Esto le llevará a Elena a la necesidad de sentirse adulada por otros, a ver que su marido no es suficiente para ella y a experimentar diversas aventuras amorosas. Al final de la novela Cesare confirma sus sospechas, que Elena le traiciona y, loco de celos, decide acabar con su vida cuando ésta había tomado la decisión de abandonarlo.

Elena es el polo opuesto a Nedda: no es humilde, no es una mujer sacrificada ni altruista. Elena representa la vanidad, la superficialidad y la belleza. En ella encontramos el prototipo de "lady", de señorita, de una mujer que busca un destino más prometedor que el de ser madre y esposa, el mundo del lujo, de la burguesía y las riquezas. Una mujer que se nos presenta como lo opuesto a una mujer Madonna, incapaz de cuidar de su hogar, pero, en cambio, sabe guardar bien las apariencias para evitar una exclusión social, aunque al final de la novela es irremediable. Además, durante toda la obra, la idea del "ser y parecer" juegan un papel muy importante. Elena es inconformista por naturaleza, ya lo decía el padre, al principio de la novela cuando dice: “iLa hemos educado como una princesa! ¡Como si hubiera tenido que casarse con un rey!" (1980: 57). La forma de ser de Elena no es fortuita, sino el producto de la educación y la influencia de la madre. La madre, como ya dijimos en el caso de Nedda y de María, vuelve a ser una figura secundaria en la novela, pero con gran influencia sobre la hija. Por ejemplo, cuando Elena se fuga de casa, Don Liborio, el padre, sólo piensa en la deshonra de él y de su familia, en la gran desgracia y en el futuro de la hija. La madre, aunque también sufre su desaparición y le hubiera gustado que las cosas pasaran de modo diferente, se muestra mucho más tranquila porque su misión como madre se ha cumplido: le ha dado una buena educación y ha podido casarla. Es decir, que Elena fue educada con un fin: el de ser buena esposa. "En fin, con tal de que se case....sólo la muerte no tiene remedio" (80)

Centrándonos en el personaje de Elena, como se ha dicho antes, es una mujer frívola y seductora que encarna la figura de mujer fatal, pero, a diferencia de La loba, como veremos más adelante, sabe guardar bien las apariencias. Quizás, la diferencia más notable entere María y Nedda y Elena sea que, desde el principio de la obra, se exalta la belleza de Elena, su cuerpo, y ello va unido a esa imagen de seductora.

Mujer fatal porque Elena es caprichosa y vive su vida como le apetece. Mujer fatal porque usa su poder de seducción y su belleza para conseguir lo que quiere. El marido encarna la figura de víctima de la seducción de su mujer ya que vive por y para satisfacer sus deseos y en este caso es el hombre el que se reduce a las órdenes de Elena aunque ésta le desprecie y no valore sus sacrificios. Toda esa resignación y frustración que Elena tiene por no haber podido cumplir sus sueños de burguesa y de una vida de lujo, la exterioriza con una necesidad casi patológica de ser admirada y amada, especialmente por hombres poderosos como el Barón y tantos otros. Sin embargo, no se puede decir que Elena tenga una carencia afectiva, ya que el marido le demuestra su amor, pero ella trasforma las carencias materiales en sentimentales y de ahí nace su necesidad de ser adulada y amada, de moverse en el ambiente de la burguesía, fiestas, teatros, de una vida más disipada que la vida en el hogar.

A Elena, la vida le da un giro cuando se queda embarazada, ya que considera la maternidad como el fin de su feminidad y la belleza destruida. Acentúa este malestar cuando dice que le aterra la idea de amamantar a su hija. Una vez que nace la niña, la maternidad parece darle la felicidad por algún tiempo, pero después le angustia como si fuera el fin de su vida disipada. Se niega a sacrificar sus sueños para quedarse en el hogar cuidando de su hija.

Al final de la novela, el día que Elena decide dejar a Cesare y marcharse, Cesare sabe que está totalmente subordinado por su poder de seducción y siempre viviría por ella. La idea de alargar su tormento y su terrible amor por ella lo aterra y decide acabar con su vida, para evitar que ella sea de otro o que lo reclame.

En esta novela, al igual que en las anteriores, nos encontramos con la muerte como sanción de una vida problemática, como la única salvación de Elena, perdida en un mundo de superficialidad y además, enajenada de la sociedad y del marido, que pone fin a su locura acabando con su vida. 


\section{LA LoBA}

Forma parte de la colección de historias breves La vida en el campo. Otra vez se elige, como en el caso de María al final de la novela, un animal feroz para representar la figura de la mujer. La loba se describe como una mujer voraz, guiada por sus instintos sexuales y carnales: la representación de la "femme fatale", de una mujer enferma, sin moral alguna, que se representa más cerca del diablo que de una figura femenina. A diferencia de Elena, la loba no guarda las apariencias porque está socialmente excluida, vista como una mujer enferma y diabólica y su único fin es el de seducir a hombres y satisfacer sus deseos sexuales. Como se describe al principio del relato, le llaman la loba porque nunca se sacia de nada, ni de las relaciones que tenía con los hombres. Las mujeres tenían miedo porque embelesaba a sus maridos e hijos con su poder de seducción, como una fuerza satánica. Además, la loba sólo se guía por sus impulsos sexuales, es decir, no presenta ningún instinto materno; rechaza la maternidad y a sus hijos. A pesar de ello, la loba tiene una hija, Maricchia, que se enamora y más tarde se casa, con el mismo hombre del que la loba está enamorada, Nanni. La loba acosa a Nanni, lo persigue y le hace caer en su juego de tentación e impulsos irrefrenables, mientras que la hija llora desconsolada al ver que la madre conquista al marido. De hecho, cuando la hija denuncia el caso, Nanni pide que por favor lo encierren para poder evitar la tentación. Al final del relato, Nanni sigue sufriendo los acosos de la loba y para poder evitarlos, decide acabar con su vida.

En el relato, la Loba se describe como una mujer delgada, no muy alta, que posee todos los rasgos de la juventud -aunque si bien ésta no es joven-y de la belleza femenina. Destaca también la figura de los senos, los ojos grandes y los labios que se describen como rojos, frescos y devoradores, que contrastan con la palidez del rostro, semejante al de una enferma. Ya del aspecto físico y la exaltación de la belleza, al igual que en Elena, sabemos que carece de virtudes y que se exalta su feminidad por encima de los valores, que recuerda a una mujer fatal, casi diabólica. Además, cuando se habla de la Loba, se identifica en ocasiones con un rol masculino: por ejemplo, cuando se describe su trabajo en el campo, de la loba se dice que trabaja con los hombres y como un hombre. Incluso es la loba quien obliga a su hija a casarse con Nanni para satisfacer sus deseos lascivos. Es decir, esa figura del padre que siempre elige el destino de la hija, con quien casarse y la vida que llevará, se transforma ahora en la figura de la Loba. La figura de la madre y la hija son polos opuestos. Mientras que la Maricchia se queda en casa amamantando a sus hijos, figura de la mujer obediente, una mujer que cuida de su casa, la vida de la loba se desenvuelve en la esfera pública.

Si tratamos el caso del adulterio Nanni, que comete el mismo crimen que la Loba, es decir, ambos mantienen relaciones sexuales -incluso el caso de Nanni es de mayor gravedad ya que está casado y la Loba no- la figura de Nanni se representa como una víctima de la seducción e incluso el lector llega a tener empatía y comprender su situación. Nanni pide ser encarcelado para poder evitar la tentación de la loba, que se representa como una figura seductora de la cual no se puede huir. La culpabilidad y el pecado sólo recaen en la Loba, un hecho común en la literatura puesto que cuando un hombre y una mujer cometen el mismo pecado, el castigo de la mujer es mucho mayor que el del hombre, y de hecho éste se suele representar como víctima.

Al final del relato, Nanni vio como única solución y salvación de la tentación, la muerte de la Loba. Otra vez se repite la idea de la muerte como un ritual de purificación del alma corrompida de la mujer y, como en el caso de María, Nedda y Elena, las desviaciones en el comportamiento femenino conllevan una punición. En este caso, el desafío del orden social, la tentación, el adulterio, la sexualidad, tienen su sanción pero sólo ésta se descarga en el personaje de la loba.

Como se puede observar, comentando el caso de Elena y la Loba, existe una gran diferencia entre ambas. Aunque las dos se consideran mujeres fatales, con gran capacidad de seducción, a Elena no se le considera enferma por naturaleza sino que las influencias externas han causado el desequilibrio de su vida. La lectura de romances, al igual que la famosa heroína de Madame Bovary, alimentó en ella unas aspiraciones imposibles de conseguir, además de la vida disipada de teatros, fiestas... A diferencia de Elena, la Loba se considera enferma y corrompida por naturaleza, portadora de pecado y casi un ser diabólico desde siempre. De naturaleza voraz y desproporcionada la Loba no tiene ninguna posibilidad de recuperarse mientras que Elena posiblemente hubiera podido recapitular su vida desde el principio en otro lugar, si Cesare no hubiera acabado con ella.

\section{Conclusión}

Verga diseña un mosaico de mujeres, desde mujeres puras e inocentes, víctimas de un destino y de una sociedad patriarcal, sacrificadas, que nos recuerdan a mártires; a mujeres perversas, con gran capacidad de seducción y egoístas. Mujeres, como ya se advirtió, turbadas, problemáticas o con problemas, y todas ellas con destinos trágicos, sin posibilidad de ser comprendidas, de expiar su culpa de otra manera que no fuera la muerte.

Resulta paradójico observar como el escritor no habla ni trata el tema específico de la condición de la mujer, sino que da vida a unos personajes y la visión de la realidad que el autor tiene, y es a través de estas figuras de las que se vale para crear un escenario siciliano de lo más real. La finalidad del estudio es, por tanto, demostrar cómo Verga escribe obras similares a las que se encuentran en todas las literaturas del siglo XIX: obras sobre mujeres escritas por hombres, donde la mujer que sobrepasa los 
valores sociales establecidos no tiene más posibilidad que la muerte para satisfacer a un público que vive inmerso en una sociedad con valores patriarcales. Además, las obras provocan en el lector la idea de justicia al observar las extremas consecuencias de una conducta socialmente inapropiada.

\section{REFERENCIAS Y BIBLIOGRAFía}

\section{Obras de Giovanni Verga}

Verga, G. (1979). Nedda en Tutte le novelle, Mondadori: Milano (1874)

(1980). Il marito di Elena, Mondadori: Milano (1881)

(1987). La Lupa en Vita dei Campi, Mondadori: Milano (1880)

(2015). Cartas de una novicia (Historia de una Curruca), Funanbulista: Madrid (1869)

\section{REFERENCIAS}

Chandler, S. B., "The Characterization of Upper Class Life in Some of Verga's Novels", Italica, 61, (1984), pp. 108-118.

D'Agostino, D., "Reminiscencias misóginas en la Lupa de Giovanni Verga", en Desde Andalucía: mujeres del Mediterráneo, Sevilla, Arcibel Editores, 2006, pp. 122-131.

De Vito, A. J., \& Verga, G., “Roba e Miseria: Motivi Dominanti nell'opera di Giovanni Verga", Italica, 31, (1954), pp. 225-236.

Ferraro, C. L. (2008). “'La novela de la tierra' de Giovanni Verga y Paz en la guerra de Miguel de Unamuno", Revista de literatura, 70, (2008), pp. 533-552.

Luperini, R, Pessimismo e verismo in Giovanni Verga, Roma, Utet, 1982.

Persico, G., Madonne, Maddalene e altre vittoriane. Modelli femminili nella letteratura inglese al tempo della regina Vittoria. I testi e il contesto, Roma, Agora, 2011.

Rosengarten, F., "Homo Siculus: Essentialism in the Writing of Giovanni Verga, Giuseppe Tomasi Di Lampedusa, and Leonardo Sciascia", en Schneider, J., Italy's "Southern Question": Orientalism in one country, Oxford, Berg, 1998, pp: 117-34. 